Central European Journal of Energetic Materials, 2016, 13(2), 397-410

ISSN 1733-7178

e-ISSN 2353-1843

\title{
GAP/DNTF Based PBX Explosives: a Novel Formula Used in Small Sized Explosive Circuits
}

\author{
Chongwei AN, Xiaomu WEN, Jingyu WANG**, Bidong WU \\ School of Chemical Engineering and Environment, \\ North University of China, \\ Taiyuan, 030051, Shanxi, P. R. China \\ *E-mail:wjywjy67@163.com
}

\begin{abstract}
With 3,4-dinitrofurazanofuroxan (DNTF) and glycidyl azide polymer (GAP) as the main explosive and binder respectively, GAP/DNTF based PBX explosives were designed, prepared and used to fill the small groove of some explosive circuits. The formulation was: DNTF 85 wt.\%, GAP 11 wt.\%, 2,4-toluene diisocyanate (TDI) and other additives making up the final $4 \mathrm{wt} . \%$. After the uncured slurry mixture was prepared by uniform mixing, a squeezing device was used to charge the circuit groove (dimensions less than $1 \mathrm{~mm} \times 1 \mathrm{~mm}$ ). Scanning electron microscope (SEM) results showed a fine charging effect. Differential Scanning Calorimetry (DSC) was used to determine the energy of activation (Ea) and the pre-factor (A) of GAP/DNTF and these were compared with those for raw DNTF. The influences and causes of it have been investigated. The experimental results for propagation reliability showed that when the dimensions of the linear groove were $0.8 \mathrm{~mm} \times 0.8 \mathrm{~mm}, 0.7 \mathrm{~mm} \times 0.7 \mathrm{~mm}, 0.6 \mathrm{~mm} \times 0.6 \mathrm{~mm}$ or $0.5 \mathrm{~mm} \times 0.5 \mathrm{~mm}, \mathrm{GAP} / \mathrm{DNTF}$ based PBX explosives can propagate explosion successfully. Furthermore, the $\mathrm{H}_{50}$ and friction sensitivity of GAP/DNTF based PBX explosives were obtained using the following mechanical sensitivity experiments. These properties are vital if GAP/DNTF based PBX explosives are to be applied in complex explosive circuits.
\end{abstract}

Keywords: explosive circuits, GAP/DNTF based PBX explosives, thermal stability, mechanical sensitivity, propagation reliability, detonation velocity

\section{Introduction}

The goals of the development of modern weapons systems are precise guidance 
and efficient damage. These depend on effective control of the targetedammunition's energy. Currently such weapons systems usually have logic explosive circuits [1] to achieve directional control of the explosion [2, 3]. Logic explosive circuits are decreasing in size and hence becoming more complex because of the special requirements of small size and detonation properties. Therefore the design of suitable mixed explosive formulations, charging method and tests of detonation performance are becoming the main concern of explosive circuits research.

Polymer-bonded explosives (PBXs) are composite materials which contain a large percentage of a high energy density compound (HEDC) (often 85-95\% by weight) mixed with a small amount of binder. They are used in a wide variety of applications, ranging from rocket propellants to the main explosive charge in munitions and detonation elements. PBXs are carefully designed to have a suitable explosive power and sufficient mechanical strength, as well as some safety features. PBXs possess good safety performance, high mechanical strength and ease of molding and other significant advantages through making full use of the high energy output of the HEDC [4] and the excellent plasticity of polymer materials. XTX-8003, XTX-8004 and HTPB/CL-20 booster explosives [5-7] are three kinds of typical PBXs used in logic explosive circuits, which use pentaerythritol tetranitrate (PETN), 1,3,5-trinitroperhydro-1,3,5-triazine (RDX) and $\varepsilon-2,4,6,8,10,12$-hexanitro-2,4,6,8,10,12-hexaazaisowurtzitane (CL-20) as HEDCs. They all meet the specific requirements of explosive circuits when combined with the polymer materials.

Studies have shown that 3,4-dinitrofurazanofuroxan (DNTF) has a high energy density, high heat of formation and high detonation velocity. It has been considered as one of the most promising HEDC. The molecular structure of DNTF is shown in Figure 1. Its density is $1.937 \mathrm{~g}^{\cdot} \mathrm{cm}^{-3}$, its detonation velocity is more than $9000 \mathrm{~m} \cdot \mathrm{s}^{-1}$ and it performs better than HMX [8-10]. In addition, DNTF has been used in modified propellant formulations because of its low friction sensitivity which helps reduce danger during production of a propellant. But so far it has not been widely used in explosive circuits. This paper explores the application of DNTF in PBX formulations used for explosive circuits. Glycidyl azide polymer (GAP) was chosen as the binder. GAP has azido groups $\left(-\mathrm{N}_{3}\right)$, which have a high nitrogen content, low mechanical sensitivity, clean products as well as other advantages [11-14]. Explosion tests have shown good effects. In the research presented in this article, we also investigated the mechanical sensitivity, thermal stability and detonation velocity of the GAP/DNTF based PBX explosives. 


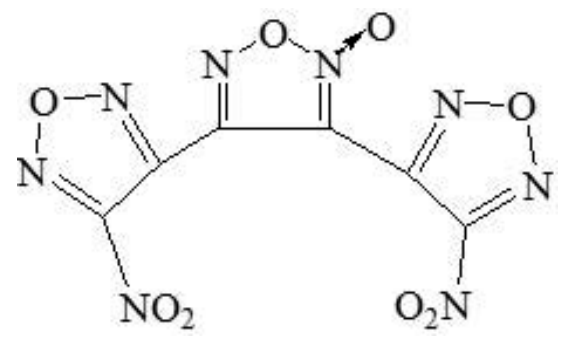

Figure 1. Molecular structure of DNTF $\left(\mathrm{C}_{6} \mathrm{~N}_{8} \mathrm{O}_{8}\right)$.

\section{Experimental Section}

\subsection{Materials}

DNTF was supplied by Gansu YinGuang Chemical Industry Co. Ltd. GAP resin with a molecular weight close to 3300 was produced by Luzhou North Chemical Industry Co. Ltd. of China. 2,4-toluene diisocyanate (TDI) was provided by Tianjin Dengke Chemical Reagent Co. Ltd. 1,4-butylene glycol (BDO) and dibutyltin dilaurate (T-12) used in this study were purchased from Beijing Chemical Plant.

The recrystallized DNTF particles used in these experiments were prepared using a solvent-nonsolvent method. Firstly, the raw DNTF was highly dissolved in dimethyl sulfoxide (DMSO), and then the solution was added to pure water to induce crystallization. The volume ratio of DMSO and water was 1:7. The dropping rate of solution is $6 \mathrm{~mL} \cdot \mathrm{min}^{-1}$ and the mixing speed was $350 \mathrm{revs} \cdot \mathrm{min}^{-1}$. Finally, the crystalline powders were filtered using a vacuum filter and dried in a vacuum freeze drier.

\subsection{Formulation}

To determine the formulation for these experiments, three aspects were taken into consideration: the specific size requirements of explosive circuits, the detonation energy and the charging technology. On the one hand, studies have shown that for a constant solid particle content, the viscosity of the colloidal mixture is significantly reduced as the particle diameter ratio $\lambda$ of the coarse and fine particles is increased from 1 to 7.25 ; but when $\lambda$ is larger than 10 , the viscosity cannot be further reduced.

On the other hand, reducing the size of the explosive particles will improve the detonation performance of the PBXs in small explosive circuits. Taking into consideration the two opposing factors above, the DNTF particle sizes 
that were used in these experiments were about 10-15 $\mu \mathrm{m}$ and 2-3 $\mu \mathrm{m}$ in a 1:1 (wt.\%) proportion. The larger particle size was achieved by grinding and the smaller by the solvent-nonsolvent method. The more DNTF that can be added, the greater the explosion energy that the PBX formula achieves. But increasing the proportion of DNTF to GAP above 85:10.5 (wt.\%) means that the explosive particles are not fully bonded by the GAP binder (see Figure 2). This meant that some of the explosive particles remained on the surface of the mixing container, adversely affecting the subsequent charging and shaping process. Therefore the formulation used in this research was as shown in Table 1.

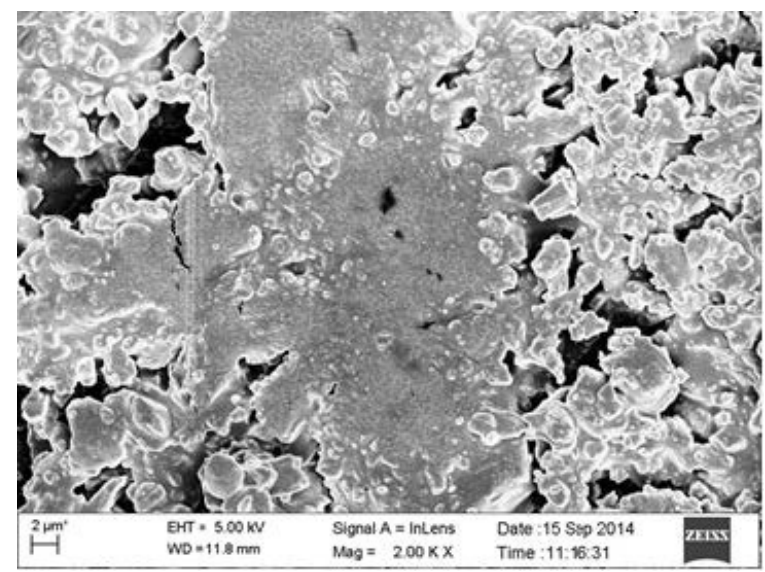

Figure 2. The bonding situation of DNTF and GAP near the critical point of 85:10 (wt.\%).

Table 1. Ingredients and their contents of the formulation used in these experiments

\begin{tabular}{|c|c|c|c|c|c|}
\hline \multicolumn{6}{|c|}{ Contents [wt.\%] } \\
\hline DNTF & GAP & TDI & BDO & T-12 & Other additives \\
\hline 85 & 11 & 1.6 & 1.4 & 0.1 & 0.9 \\
\hline
\end{tabular}

\subsection{Ingredients characterization}

A DX-2700 diffractometer (Dandong Haoyuan Instrument Co., Ltd., China) was used to determine the crystal types of the refined DNTF and the GAP/DNTF by $\mathrm{X}$-ray diffractometry (XRD). The morphology characterization was performed using an SU8020 scanning electron microscope (SEM) (Hitachi Ltd., Japan). The thermal decomposition behavior of the DNTF/GAP ingredients was studied using a differential thermal analyzer (NETZSCH 204HP) under a gas pressure 
of 2.0 MPa. This pressure was achieved by filling the crucible with nitrogen. Heating rates of $1,2,5$ and $10 \mathrm{~K} \cdot \mathrm{min}^{-1}$ were used.

\subsection{Charging and curing process}

After the DNTF particles were fully mixed with the GAP, TDI and other additives were added to the mixture during stirring. The pre-cured explosive slurry was then placed in the injection device and squeezed under pressure into the groove in the substrate. The substrate was kept at about $60{ }^{\circ} \mathrm{C}$ using a hot platform before the charging process in order to guarantee that the groove was fully filled with the explosive slurry. Finally, the substrate was placed in a vacuum oven at $70{ }^{\circ} \mathrm{C}$ to cure it completely. The structure of the GAP used in this study is shown below. The polymer has only hydroxyl end groups.

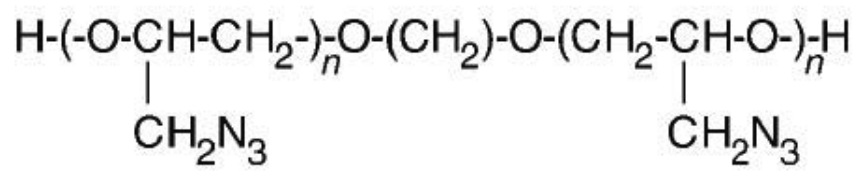

Figure 3 shows the detonation substrate after the charging and curing process. An EVO18 scanning electron microscope (SEM) (Carl Zeiss Ltd., Germany) was employed to observe the quality of the morphology of the GAP/DNTF based PBX explosives after the charging and curing processes.

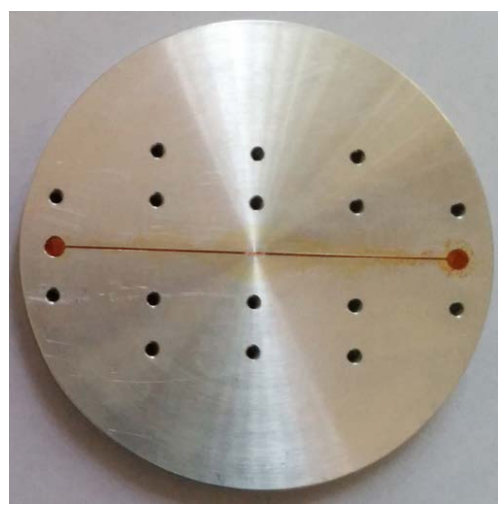

Figure 3. The detonation substrate after the charging and curing processes. 


\subsection{Propagation reliability experiment of DNTF/GAP based PBX explosives}

Propagation reliability is a significant property of the DNTF/GAP based PBX explosives if they are to be applied in small scale explosive circuits. Propagation reliability tests were conducted after the curing process. Linear grooves of dimensions $0.8 \mathrm{~mm} \times 0.8 \mathrm{~mm}, 0.7 \mathrm{~mm} \times 0.7 \mathrm{~mm}, 0.6 \mathrm{~mm} \times 0.6 \mathrm{~mm}$ and $0.5 \mathrm{~mm} \times 0.5 \mathrm{~mm}$ were charged with the GAP/DNTF based PBX explosive. Then a flame detonator was fixed in the middle of the linear groove. After activation of the flame detonator, it can be observed whether the detonation propagation is reliable or not.

\subsection{Tests of detonation velocity and mechanical sensitivity}

The detonation velocity of the GAP/DNTF based PBX explosive in a groove was measured using velocity gauges which were installed on the surface of the charged groove. After the explosives were initiated by the flame detonator, the run time of the detonation wave between the two sensors of the velocity gauge was recorded. The detonation velocity was calculated from the distance between the two sensors and the measured time of propagation. In the impact sensitivity test, an ERL type 12 drop hammer apparatus was used in which the mass of the drop weight was $2.500 \pm 0.005 \mathrm{~kg}$ and the sample mass was $35 \pm 1 \mathrm{mg}$. All tests were performed at room temperature. The results were expressed as the critical dropheight for $50 \%$ explosion probability $\left(\mathrm{H}_{50}\right)$ and the standard deviation $(\mathrm{S})$. The larger the value of $\mathrm{H}_{50}$, the lower the impact sensitivity, i.e. the better the impact insensitivity [15]. Friction sensitivity was measured according to the explosion probability method of GJB-772 using a Swing Friction Sensitivity Tester.

\section{Results and Discussion}

\subsection{XRD test results}

Figure 4 shows the results of an X-ray diffraction study of the crystal structure. This study indicates that the peaks for GAP/DNTF have almost the same diffraction angles as those of raw DNTF and DNTF refined by the solventnonsolvent method, implying that the DNTF in GAP/DNTF based PBXs have the same crystal structure as raw DNTF. However, most peaks in the XRD patterns of GAP/DNTF are broadened and of lower intensity compared to those of raw DNTF. This is due to the fact that the X-ray yield strength decreases with decreasing particle size and also that the GAP coated onto the surface of the crystalline DNTF particles is amorphous and non-crystalline [16]. 


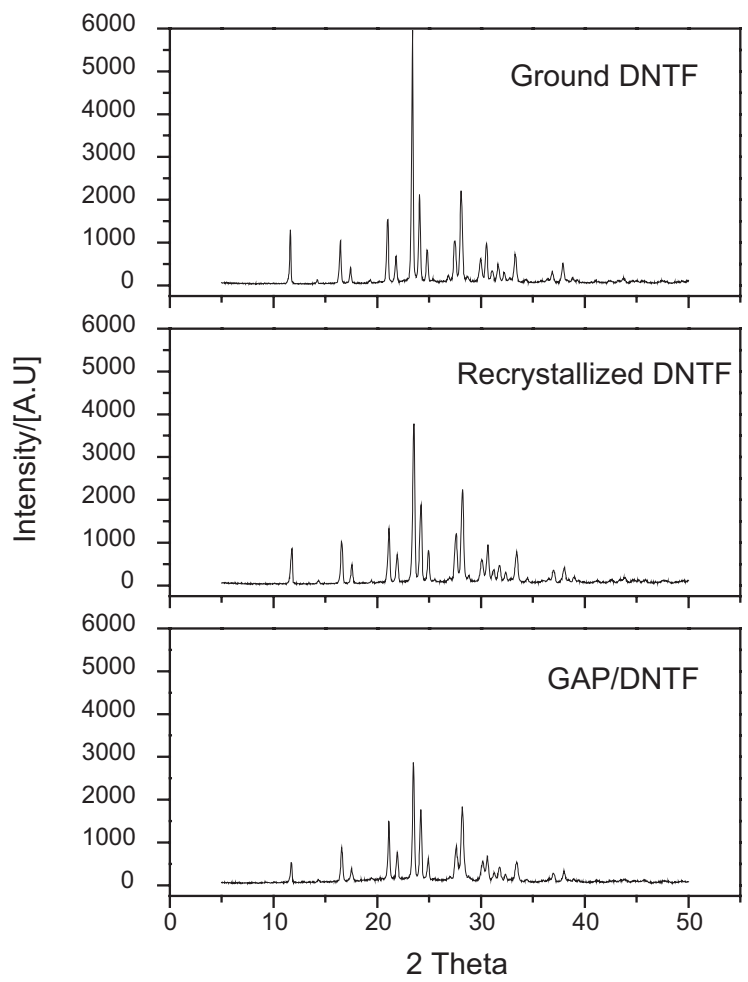

Figure 4. XRD test results.

\subsection{SEM test results}

SEM images of the two kinds of DNTF fillers are shown in Figure 5. From Figure 5, it can be seen that the shapes of both types DNTF particles are mostly flaky. The particle sizes of ground and recrystallized DNTF are about 10-15 $\mu \mathrm{m}$ and 2-3 $\mu \mathrm{m}$ respectively. The flakiness of the crystals may be related to the molecular structure of DNTF and makes for a high packing density and hence high energy of explosion [17]. 


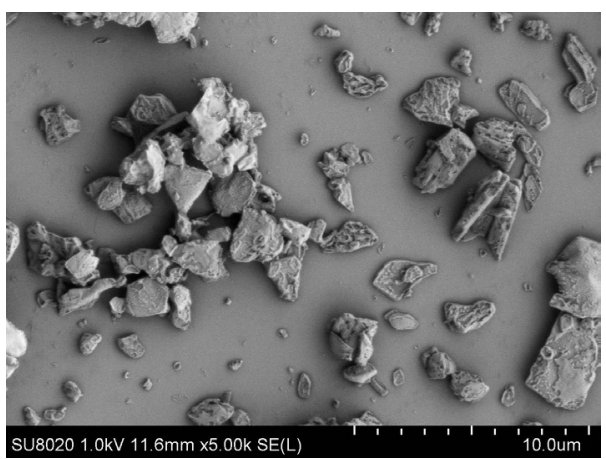

a.

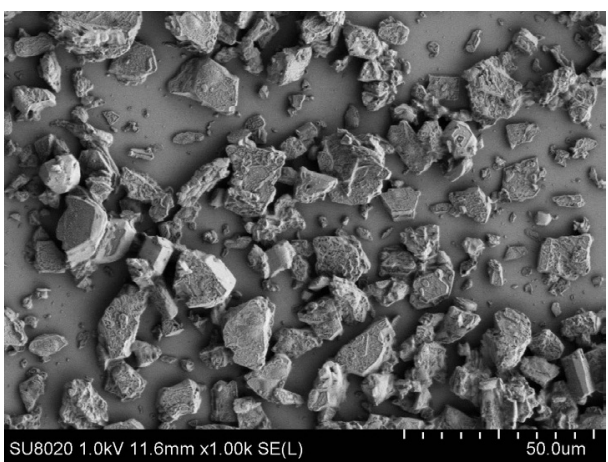

b.

Figure 5. SEM images of the two kinds of DNTF fillers, a: recrystallized DNTF; b: ground DNTF.

\subsection{DSC test results}

Figure 6 shows the DSC curves for raw DNTF and GAP/DNTF at 1, 2, 5 and $10 \mathrm{~K} \cdot \mathrm{min}^{-1}$ heating rates. An endothermic peak $\left(108.9-109.6{ }^{\circ} \mathrm{C}\right) \mathrm{can}$ be seen for the four heating rates in Figure 6 (A, B). The DSC results show that DNTF began to melt at about $109{ }^{\circ} \mathrm{C}$. For the same sample, the exothermic peak temperatures decreased at a slower heating rate. This observation proves that thermal decomposition occurs more easily when the heating rate is slower. The exothermic peak temperatures of the GAP/DNTF are lower than for raw DNTF.
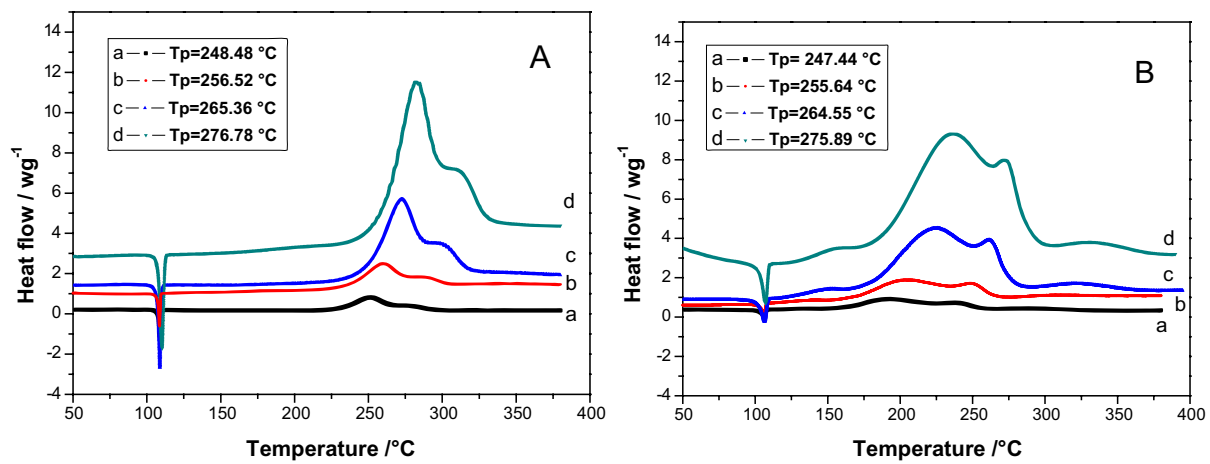

Figure 6. DSC curves of raw DNTF (A) and GAP/DNTF (B) at heating rates of (a) $1 \mathrm{~K} \cdot \mathrm{min}^{-1}$, (b) $2 \mathrm{~K} \cdot \mathrm{min}^{-1}$, (c) $5 \mathrm{~K} \cdot \mathrm{min}^{-1}$ and (d) $10 \mathrm{~K} \cdot \mathrm{min}^{-1}$.

The thermal decomposition kinetics parameters of raw DNTF and the GAP/ DNTF PBX can be calculated using the Kissinger method (Equation 1) [18]. 


$$
\ln \frac{\beta_{i}}{T_{p i}^{2}}=\ln \frac{A R}{\mathrm{E}}-\frac{E}{R T_{p i}}
$$

where $\beta_{i}$ is the heating rate in $\mathrm{K} \cdot \mathrm{min}^{-1}, T_{p i}$ is the temperature of the exothermic peak at a heating rate of $\beta_{i}$ in $\mathrm{K} \cdot \mathrm{min}^{-1}, E$ is the activation energy in $\mathrm{J} \cdot \mathrm{mol}^{-1}, A$ is the pre-exponential factor, and $R$ is the gas constant $\left(8.314 \mathrm{~J} \cdot \mathrm{mol}^{-1} \cdot \mathrm{K}^{-1}\right)$.

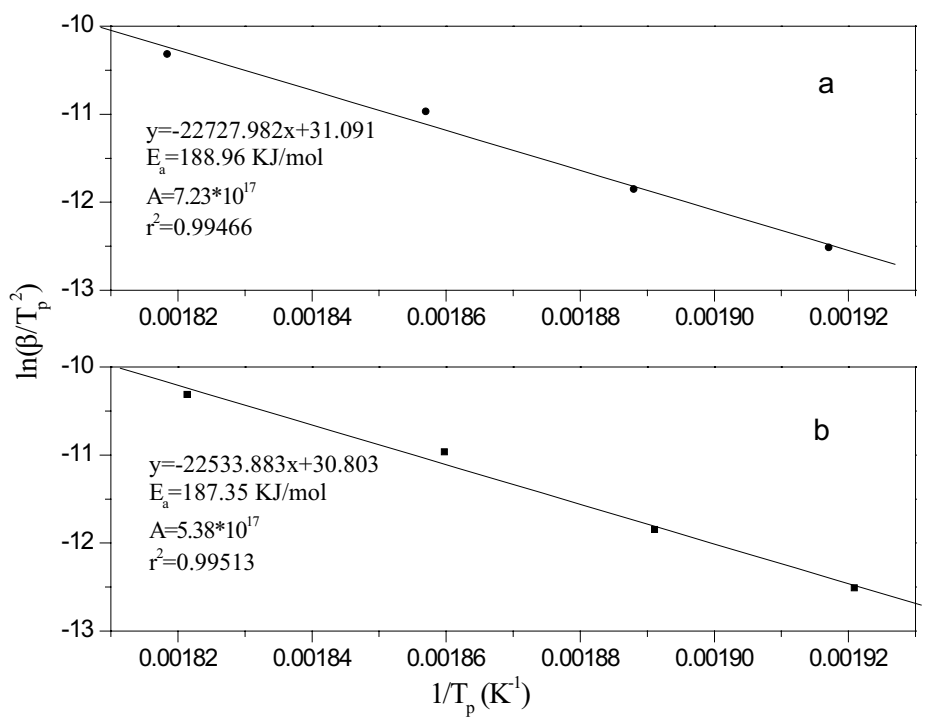

Figure 7. Kissinger plot for (a) raw DNTF and (b) GAP/DNTF.

As shown in Figure 7, a straight line is obtained when $\ln \left(\beta_{i} / T_{p i}{ }^{2}\right)$ is plotted against $1 / T_{p i}$. The activation energy $E$ can be calculated from the slope $(-E / R)$. The pre-exponential factor $A$ can be calculated from the intercept $[\ln (A R / E)]$. The results show that the activation energy for GAP/DNTF is slightly different to that of raw DNTF being $187.35 \mathrm{~kJ} \cdot \mathrm{mol}^{-1}$ as compared with $188.96 \mathrm{~kJ} \cdot \mathrm{mol}^{-1}$ for raw DNTF .

\subsection{Shape Quality Test results after the charging and curing progress}

Figure 8 presents data on the quality of the shape of cured GAP/DNTF based PBX explosive in grooves. The quality is assessed using the position of the surface and the cross-section. Good charging and curing means that there are no cracks, shrinkage or other defects. 

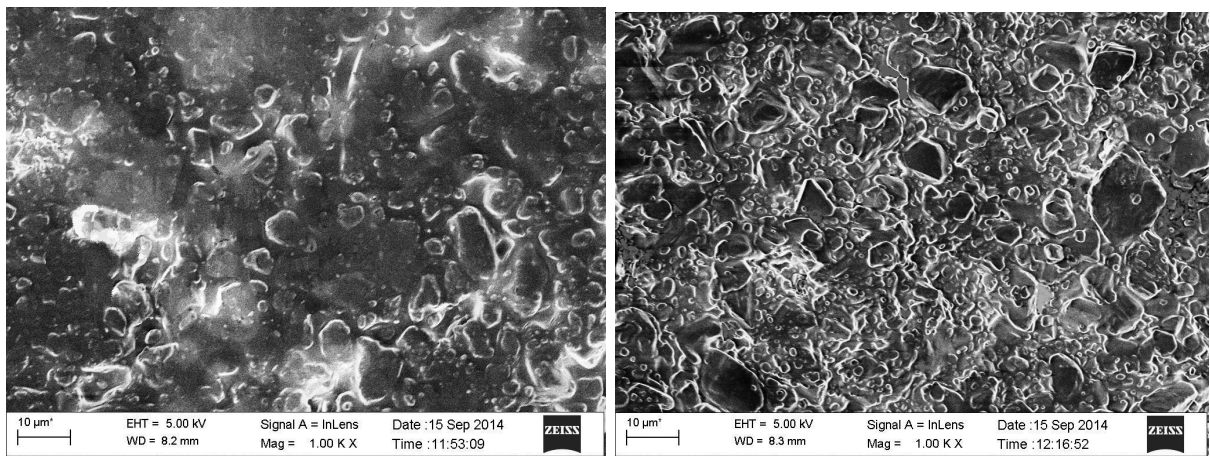

Figure 8. The shape quality of the surface and cross-section.

\subsection{Density test results}

The urizar method [19] (volume plus method) can be used to calculate the theoretical density of a PBX due to the mutual insolubility of the main ingredients. The densities of charges in grooves of different dimensions were estimated on the basis of their volumes and masses. The charge volume can be determined from the groove size. The charge mass can be obtained from the difference in mass between an empty steel substrate plate and one with a charge. The results are shown in Table 2.

Table 2. Theoretical and measured densities of DNTF/GAP charges in grooves of different sizes

\begin{tabular}{|c|c|c|c|c|c|}
\hline \multirow{2}{*}{ Groove size } & Theoretical density & \multicolumn{4}{|c|}{ Measured density $\left[\mathrm{g} \cdot \mathrm{cm}^{-3}\right]$} \\
\cline { 3 - 6 } & {$\left[\mathrm{g} \cdot \mathrm{cm}^{-3}\right]$} & 1 & 2 & 3 & Average \\
\hline $0.8 \mathrm{~mm} \times 0.8 \mathrm{~mm}$ & 1.780 & 1.636 & 1.638 & 1.637 & 1.637 \\
\hline $0.7 \mathrm{~mm} \times 0.7 \mathrm{~mm}$ & 1.780 & 1.633 & 1.637 & 1.635 & 1.635 \\
\hline $0.6 \mathrm{~mm} \times 0.6 \mathrm{~mm}$ & 1.780 & 1.634 & 1.635 & 1.636 & 1.635 \\
\hline $0.5 \mathrm{~mm} \times 0.5 \mathrm{~mm}$ & 1.780 & 1.635 & 1.634 & 1.639 & 1.638 \\
\hline
\end{tabular}

\subsection{Propagation Reliability Test results}

Experimental results for the propagation reliability show that when the sizes of the linear grooves were $0.8 \mathrm{~mm} \times 0.8 \mathrm{~mm}, 0.7 \mathrm{~mm} \times 0.7 \mathrm{~mm}, 0.6 \mathrm{~mm} \times 0.6 \mathrm{~mm}$, $0.5 \mathrm{~mm} \times 0.5 \mathrm{~mm}, \mathrm{GAP} / \mathrm{DNTF}$ based PBXs can propagate explosion successfully. 

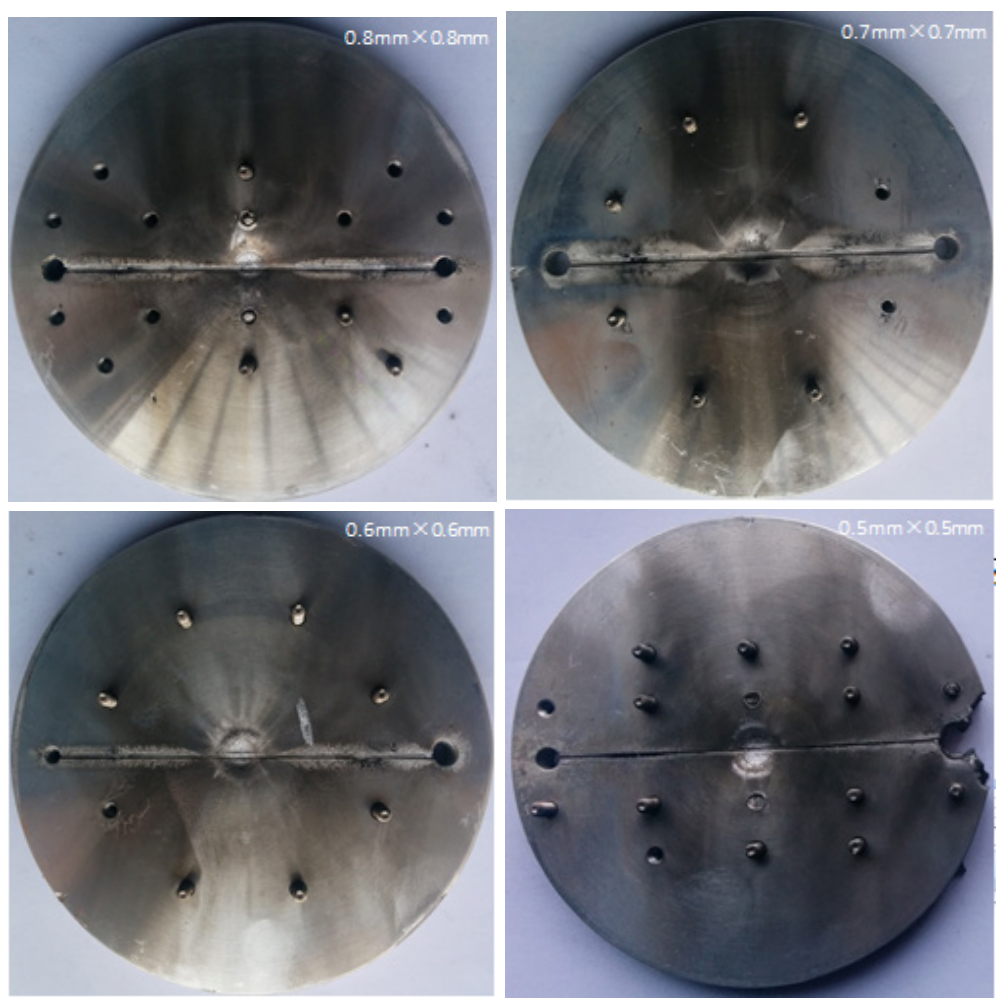

Figure 9. Propagation Reliability Test photos.

\subsection{Detonation Velocity Test results}

The following Equations 2 [19] were used to estimate the theoretical detonation velocity.

$$
\begin{aligned}
& D_{\text {max }}=\sum D_{i} a_{v_{i}} \\
& a_{v_{i}}=\rho_{\max } \frac{g_{i}}{\rho_{i \max }} \\
& D=\frac{D_{\max }}{4}+\frac{3}{4} \frac{D_{\max }}{\rho_{\text {max }}} \rho_{0}
\end{aligned}
$$

where $D_{\max }$ is the theoretical detonation velocity, $D_{i}$ is the theoretical detonation velocity in an ingredient; $a_{v i}$ is the volume fraction of the $i^{\text {th }}$ ingredient, $\rho_{\max }$ is the theoretical density of the explosive compound, $g_{i}$ is the ingredient quality, $\rho_{i \max }$ is the theoretical density of the $i^{\text {th }}$ ingredient, $\rho_{0}$ is the measured density, and 
$D$ is the theoretical detonation velocity when $\rho_{0}$ is the measured density. The theoretical detonation velocity of pure DNTF is $9250 \mathrm{~m} \cdot \mathrm{s}^{-1}$ and the theoretical density of DNTF is $1.937 \mathrm{~g} \cdot \mathrm{cm}^{-3}$ [20]. These properties are almost the same as 3,4-bis(4'-nitrofurazan-3'-yl)furoxan (BNFF) [21]. Then after the parameters of other additives are obtained, the theoretical detonation velocities of GAP/DNTF based PBXs can be calculated using Equations 2. The detonation velocities of GAP/DNTF based PBXs were also measured in a groove of dimension $0.8 \mathrm{~mm} \times 0.8 \mathrm{~mm}$. The results are shown in Table 3 .

Table 3. Detonation velocity results of GAP/DNTF based PBXs in a groove of dimension $0.8 \mathrm{~mm} \times 0.8 \mathrm{~mm}$

\begin{tabular}{|c|c|c|c|c|}
\hline $\begin{array}{c}\rho_{\max } \\
{\left[\mathrm{g} \cdot \mathrm{cm}^{-3}\right]}\end{array}$ & $\begin{array}{c}\rho \text { (measured) } \\
{\left[\mathrm{g} \cdot \mathrm{cm}^{-3}\right]}\end{array}$ & $\mathrm{D}_{\max }\left[\mathrm{m} \cdot \mathrm{s}^{-1}\right]$ & $\begin{array}{c}\mathrm{D} \text { (calculated) } \\
{\left[\mathrm{m} \cdot \mathrm{s}^{-1}\right]}\end{array}$ & $\begin{array}{c}\mathrm{D} \text { (measured) } \\
{\left[\mathrm{m} \cdot \mathrm{s}^{-1}\right]}\end{array}$ \\
\hline 1.780 & 1.637 & 8334 & 7832 & 7362 \\
\hline
\end{tabular}

\subsection{Mechanical Sensitivity Test results}

The mechanical sensitivity test results for DNTF, GAP/DNTF, HMX and PBXN-5 are shown in Table 4 . They show that the average drop height $\mathrm{H}_{50}$ for GAP/DNTF is around $13.0 \mathrm{~cm}$ higher than for DNTF, indicating that the impact insensitivity of GAP/DNTF is better than for DNTF. The friction sensitivity of GAP/DNTF is also better than for pure DNTF and PBXN-5. This is because GAP can fully fill the spaces between explosive particles so as to provide shock absorption under mechanical collision. The tiny size and spherical shape of particles in the sample can also decrease the mechanical sensitivity. The results also show that GAP/DNTF based PBXs possess an equivalent impact insensitivity to that of PBXN-5 and a better impact sensitivity than that of CL-20/HTPB/TDI (drop height $\mathrm{H}_{50} / \mathrm{cm}, 20.7$; standard deviation/S, 0.085) [22].

Table 4. Mechanical sensitivity test results

\begin{tabular}{|c|c|c|c|c|c|c|}
\hline \multirow{2}{*}{ Samples } & \multicolumn{5}{|c|}{ Impact sensitivity, $\mathrm{H}_{50}[\mathrm{~cm}]$} & $\begin{array}{c}\text { Friction } \\
\text { sensitivity, } \\
\mathrm{P}[\%]\end{array}$ \\
\cline { 2 - 7 } & $\begin{array}{c}\text { Experi- } \\
\text { ment 1 }\end{array}$ & $\mathrm{S}(1)$ & $\begin{array}{c}\text { Experi- } \\
\text { ment } 2\end{array}$ & $\mathrm{~S}(2)$ & Average & Experiments \\
\hline DNTF $(2-3 \mu \mathrm{m})$ & 25.9 & 0.08 & 25.3 & 0.06 & 25.6 & 13 \\
\hline DNTF $(15-20 \mu \mathrm{m})$ & 25.1 & 0.07 & 24.9 & 0.08 & 25.0 & 12 \\
\hline HMX & 25.8 & 0.06 & 25.6 & 0.07 & 25.7 & 100 \\
\hline GAP/DNTF & 38.2 & 0.10 & 38.4 & 0.09 & 38.3 & 0 \\
\hline PBXN-5 & 40.5 & 0.09 & 41.1 & 0.11 & 40.8 & 16 \\
\hline
\end{tabular}




\section{Conclusions}

For the purpose of obtaining a new kind of PBX circuit, the following formulation was tested: DNTF 85 wt.\%, GAP 11 wt. $\%$, TDI 1.6 wt. $\%$ and other additives $2.4 \mathrm{wt} . \%$. A squeezing device was used for charging grooves with GAP/ DNTF explosive. This achieved the goal of charging grooves of dimension $0.5 \mathrm{~mm} \times 0.5 \mathrm{~mm}$ and larger. SEM images showed that the quality of the explosive material in the charged grooves was good: no shrinkage, cracks or other defects. DSC tests showed that the activation energies $\left(\mathrm{E}_{\mathrm{a}}\right)$ of raw DNTF and GAP/DNTF were $188.96 \mathrm{~kJ} \cdot \mathrm{mol}^{-1}$ and $187.35 \mathrm{~kJ} \cdot \mathrm{mol}^{-1}$, respectively. This technique indicates that the two explosives have equivalent thermal decomposition characteristics and also that GAP does not have a bad effect on the compatibility of the ingredients. Experimental results from propagation reliability tests showed that GAP/DNTF based PBXs could propagate explosion successfully in the linear grooves of size $0.8 \mathrm{~mm} \times 0.8 \mathrm{~mm}, 0.7 \mathrm{~mm} \times 0.7 \mathrm{~mm}, 0.6 \mathrm{~mm} \times 0.6 \mathrm{~mm}$ and $0.5 \mathrm{~mm} \times 0.5 \mathrm{~mm}$. When the charge density in the grooves reached $1.637 \mathrm{~g} \cdot \mathrm{cm}^{-3}$, the detonation velocity can reach $7362 \mathrm{~m} \cdot \mathrm{s}^{-1}$. Furthermore, the $\mathrm{H}_{50}$ of GAP/DNTF based PBXs was $38.3 \mathrm{~cm}$ for its impact sensitivity. It also possesses good friction insensitivity. Properties such as these (especially the propagation reliability in small grooves) give GAP/DNTF based PBXs the potential to be applied to complex explosive circuits.

\section{References}

[1] Silvia D.A., Explosive circuits, US Patent 3,728,965, 1973.

[2] Meyere W.H., On the Design of Logic Explosive Circuits, Proc. 12 $2^{\text {th }}$ Int. Symp. Explosives \& Pyrotechnics, 1984.

[3] Silvia D.A., Explosive Logic Safing Device, US Patent 4,412,493, 1983.

[4] Michels H.H., Theoretical Research Investigation of High Energy Species, Report No. AD-A 319054, 1996.

[5] Harris B.W., Oil/High Explosive Compatibility Study. Selection of Safing Fluids for Damaged Explosives Assemblies, Propellants Explos. Pyrotech., 1984, 9(1), 7-11.

[6] Wulfman D.S., Sitton O., Nixon F.T., Reformulation of Solid Propellants and High Explosives: an Environmentally Benign Means of Demilitarizing Explosive Ordnance, Can. J. Chem. Eng., 1997, 75(5), 899-912.

[7] Wang J.Y., An C.W., Li G., Liang L., Xu W.Z., Wen K., Preparation and Performances of Castable HTPB/CL20 Booster Explosives, Propellants Explos. Pyrotech., 2011, 36(1), 34-41.

[8] Hu H.X., Zhang Z.Z., Zhao F.Q., Xiao C., Wang Q.H., A Study on the Properties 
and Application of High Energy Density Material DNTF, J. Acta Armamentarii, 2004, 25(2), 155-158.

[9] Wang Q.H., Properties of DNTF-based Melt-cast Explosives, Chin. J. Explos. Propellants, 2003, 26(3),57-59.

[10] Hu H.X., Qin G.M., Zhang Z.Z., 3,4-Di-nitrofurazanfuroxan Explosive, China Patent 02101092. 7, 2002.

[11] Shi M.D., Research Progress of GAP and GAP Propellant, Chin. J. Explos. Propellants, 1994, 17(1), 9-16.

[12] Tang C.J., Lee Y.J., Litzinger T.A., Simultaneous Temperature and Species Measurements of the Glycidyl Azide Polymer (GAP) Propellant During LaserInduced Decomposition, Combust. Flame, 1999, 117(1), 244-256.

[13] Kubota N., Sonobe T., Combustion Mechanism of Azide Polymer, Propellants Explos. Pyrotech, 1988, 13(6), 172-177.

[14] Frankel M.B., Grant L.R., Flanagen J.E., Historical Development of Glycidyl Azide Polymer, J. Propul. Power, 1992, 8(3), 560-563.

[15] Experimental Methods of Sensitivity and Safety (in Chinese), National Military Standard of China, GJB/772A-97, 1997.

[16] Yang G.C., Nie F.D., Huang H., Preparation and Characterization of Nano-TATB Explosive, Propellants Explos. Pyrotech., 2006, 31(5), 390-394.

[17] Zhou Y.S., Zhang Z.Z., Li J.K.., Crystal Structure of 3,4-Dinitrofurazanofuroxan, Chin. J. Explos. Propellants, 2005, 28(2), 43-46.

[18] Kissinger H.E., Reaction Kinetics in Differential Thermal Analysis, Anal. Chem., 1957, 29(11), 1702-1706.

[19] Dobratz B.M., Crawford P.C., Properties of Chemical Explosives and Explosive Simulants, Report No. UCR-S1319, 1974.

[20] Hu H.X., Zhang Z.Z., Zhao F.Q., A Study on the Properties and Application of High Energy Density Material DNTF, Acta Armamentari, 2004, 25(2), 155-158.

[21] Stepanov A.I., Dashko D.V., Astrat'ev A.A., 3,4-Bis(4'-nitrofurazan-3'-yl)furoxan: a Melt Cast Powerful Explosive and a Valuable Building Block in 1,2,5-Oxadiazole Chemistry, Cent. Eur. J. Energ. Mater, 2012, 9(4), 329-342.

[22] Li H.X., Wang J.Y., An C.W., Study on the Rheological Properties of CL-20/HTPB Casting Explosives, Cent. Eur. J. Energ. Mater., 2014, 11(2), 237-255. 